\title{
Mario Marchisio, La chiarezza possibile
}

\section{Wilma Proglio}

\section{(2) OpenEdition}

\section{Journals}

\section{Edizione digitale}

URL: http://journals.openedition.org/studifrancesi/28451

DOI: 10.4000/studifrancesi.28451

ISSN: 2427-5856

\section{Editore}

Rosenberg \& Sellier

\section{Edizione cartacea}

Data di pubblicazione: 31 décembre 2006

Paginazione: 665

ISSN: 0039-2944

\section{Notizia bibliografica digitale}

Wilma Proglio, « Mario Marchisio, La chiarezza possibile », Studi Francesi [Online], 150 (L | III) | 2006

online dal 30 novembre 2015, consultato il 08 novembre 2020. URL : http://journals.openedition.org/ studifrancesi/28451; DOI : https://doi.org/10.4000/studifrancesi.28451

\section{Questo documento è stato generato automaticamente il 8 novembre 2020.}

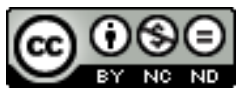

Studi Francesi è distribuita con Licenza Creative Commons Attribuzione - Non commerciale - Non opere derivate 4.0 Internazionale. 


\title{
Mario Marchisio, La chiarezza possibile
}

\author{
Wilma Proglio
}

\section{NOTIZIA}

MARIO MARCHISIO, La chiarezza possibile, Alessandria, Edizioni dell’Orso, 2005, pp. 190.

1 Questo libro si configura come una raccolta di saggi centrati su una funzione fondamentale della parola letteraria, quella cioè di "dare ordine al caos", assumendo un punto di vista chiarificatore sulla realtà e soprattutto sulle remote istanze che agitano l'animo umano.

2 Marchisio si sofferma su svariate opere (in prosa e in poesia) dei principali autori delle letterature europee. Per quanto riguarda l'area francese, sono presenti quattro saggi. Nel primo, dal titolo "Da Dio al lettore" (pp. 39-41), Marchisio riflette sulla scelta da parte di Rousseau di intitolare la sua opera autobigrafica Confessions, rievocando inevitabilmente le Confessioni di Sant'Agostino. Entrambi, sottolinea l'autore, esordiscono appellandosi a Dio quale garante della veridicità di quanto narrato, ma il philosophe prosegue poi accantonando il riferimento divino e facendo delle sue confessioni non un atto di umiltà bensì di "autogiustificazione e [...] commiserazione di sé” (p. 41).

3 Nel saggio I corpi inquieti (pp. 51-64), Marchisio si sofferma sulla spasmodica ricerca del bello da parte di Théophile Gautier. Nella concezione di quest'ultimo, l'arte è il solo strumento in grado di conferire eternità alla bellezza ed il mondo del sogno è lo strumento concesso all'uomo per sperimentare la dimensione atemporale della vita oltre la morte. Emblematico da questo punto di vista è il racconto La morte amoureuse, nel quale il sacerdote Romuald è conteso tra vita ecclesiastica il giorno e visite peccaminose la notte. Marchisio sottolinea come la grande novità di questo racconto non sia la lotta tra bene e male, bensì la coesistenza e l'oscillazione tra i due all'interno della stessa anima. 
4 In Verità procrastinate (pp. 72-75), Marchisio si muove nelle memorie proustiane della Recherche, sottolineando l'inesorabile opera dell'oblio. In Elogio dell'asprezza (pp. 101-105), vengono presi in esame i protagonisti di tre opere di Flaubert - Emma Bovary, Frédéric Moreau e Félicité - tre personaggi accomunati dal tema del fallimento e dalla parabola umana illusione-gioia-delusione-amarezza. L'autore applica efficacemente al realismo flaubertiano l'espressione ossimorica, mutuata da Zanzotto, di "ricchissimo nihil", definizione con la quale Marchisio si riferisce all'impietosa distruzione della realtà dei personaggi flaubertiani, nella cui drammatica vacuità è però contenuta una ricchezza inestinguibile di passioni e attese. L'unico rimedio contro il dolore a cui è votato l'essere umano consiste nell'ascesi dell'arte. 